\title{
Disproportionately severe memory deficit in relation to normal intellectual functioning after closed head injury
}

\author{
H S LEVIN, * F C GOLDSTEIN, $\dagger$ W M HIGH JR, * H M EISENBERG* \\ From the Division of Neurosurgery* and Department of Neurology, $\dagger$ The University of Texas Medical Branch, \\ Galveston, Texas, USA
}

SUMMARY The presence of disproportionate memory impairment with relatively preserved intellectual functioning was examined in 87 survivors of moderate or severe closed head injury. Approximately one-fourth of the patients tested at 5 to 15 and/or 16 to 42 months after injury manifested defective memory on both auditory and pictorial measures despite obtaining Wechsler Verbal and Performance Intelligence Quotients within the average range. The findings indicate that disproportionately severe memory deficit persists in a subgroup of closed head injured survivors which is reminiscent in some cases of the amnesic disturbance arising from other causes. Evaluation of long term memory in relation to cognitive ability could potentially identify important distinctions for prognosis and rehabilitation in head injured patients.

Russell ${ }^{1}$ reported that residual memory disturbance was present in $23 \%$ of over 1000 servicemen who were convalescing from closed head injury (CHI) and in $50 \%$ of the most severely injured patients. Recent studies administering psychometric and experimental tasks to characterise the residual impairment of long term memory after head trauma ${ }^{2-8}$ have varied in the neurological indices employed to analyse severity of CHI. The Glasgow Coma Scale (GCS) ${ }^{9}$ and durations of coma and posttraumatic amnesia (PTA) have been positively, albeit inconsistently, related to residual memory problems. ${ }^{2-68}$ While less frequently analysed, the effects of focal intracranial lesions on memory have been relatively unimpressive when compared with the degree and duration of impaired consciousness. ${ }^{2-6810}$

Whether memory deficit is invariably an expression of global cognitive impairment or a relatively specific sequel of $\mathrm{CHI}$ remains unclear. Few studies have concurrently administered psychometric tests of intellectual function and memory to head injured patients ${ }^{2811}$ or have analysed dissociations in performance similar to investigations of amnesia sec-

Address for reprint requests: Harvey S. Levin, Ph.D., Division of Neurosurgery D-73, The University of Texas Medical Branch, Galveston, Texas 77550, USA.

Received 15 December 1987 and in revised form 13 May, 1988. Accepted 13 June 1988 ondary to alcoholic Korsakoff syndrome or herpes encephalitis. ${ }^{12-15}$ Following the approach which identifies cases of memory impairment with relatively preserved intellectual function in studies of amnesia (cf. 16), we determined the frequency of specific memory deficit persisting over two follow-up intervals in survivors of moderate and severe CHI. Given our prediction of more impressive neurobehavioural recovery after moderate $\mathrm{CHI}$, we anticipated that concomitant memory and cognitive deficits would be found primarily in the severely injured patients.

Method

\section{Subjects}

To accrue a sample in whom memory prior to head trauma was relatively homogeneous and intact, we studied patients who were between the ages of 18 and 30 years $(M=22.6$, $\mathrm{SD}=3.7$ ) at the time of injury and had no previous history of $\mathrm{CHI}$, substance abuse, neuropsychiatric illness or subnormal intelligence. In view of recent studies documenting recovery of memory within 3 months after a mild CHI, ${ }^{17-19}$ this investigation was confined to consecutive admissions to the neurosurgery service of moderate or severe injuries. In addition, we selected patients from whom complete neurological data were prospectively collected (including serial GCS scores) who were free of residual aphasic deficit. ${ }^{20}$

Table 1 summarises the demographic and clinical characteristics of the 87 survivors who fulfilled the selection criteria and comprised the sample. Thirty-three patients $(25 \mathrm{men}$, eight women) sustained moderate injuries (that is, admission 
Table 1 Demographic and clinical characteristics of the head injured patients*

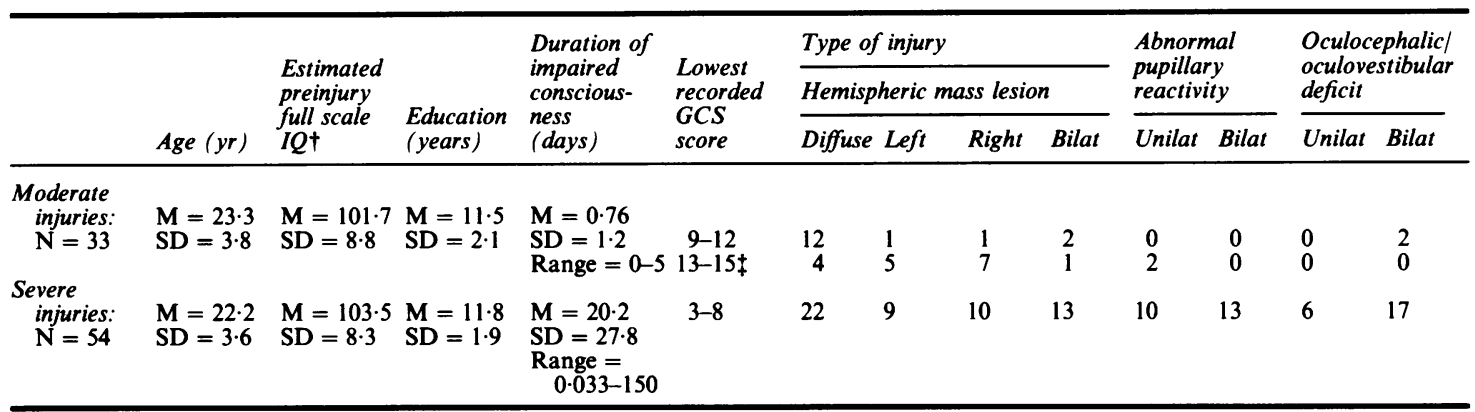

* M = mean; SD = standard deviation; GCS = Glasgow Coma Scale.

†Estimated by regression equation based on demographic variables (Wilson et al, 1978).

†Classified as moderate CHI because of neurologic deficit, abnormal CT scan showing a focal intracranial lesion and/or elevation of a depressed skull fracture.

GCS score 9-12 or greater than 12 with one or more of the following complications: neurological deficit, computed tomographic and/or surgical findings indicating an intracranial lesion and/or cerebral swelling, or depressed skull fracture with dural laceration). No patient classified as moderate CHI deteriorated to a GCS score <9. Fifty-four patients (46 men, eight women) had severe injuries (that is, postresuscitation GCS score $<8$ with no eye opening, inability to follow commands, and failure to utter comprehensible speech). Mechanisms of injury and corresponding percentages for the moderate and severe $\mathrm{CHI}$ groups were: motor vehicle accident $(67 \%, 86 \%)$, fall $(6 \%, 4 \%)$, struck with blunt object $(3 \%, 4 \%)$, sports $(3 \%, 2 \%)$, assault $(15 \%$, $4 \%)$, and explosion $(6 \%, 0 \%)$.

As reflected in table 1 , there were no significant differences between the groups with respect to age, $F(1,85)=1.41$, $p>0.05$, education, $F(1,85)=0.41, p>0.05$, or estimated premorbid Full Scale Intelligence Quotient (IQ), ${ }^{21}$ $\mathrm{F}(1,85)=0.99, \quad \mathrm{p}>0.05$, calculated according to a regression equation based on demographic variables. ${ }^{22}$ Nineteen neurologically intact control subjects of comparable age $(M=23 \cdot 3, S D=4 \cdot 0)$ were tested to evaluate the normal variation between memory and intellectual functioning. The estimated premorbid Full Scale IQs of the two patient groups (table 1) and the actual IQs obtained by the controls $(M=102 \cdot 8, S D=10 \cdot 3)$ were not significantly different, $F(2,103)=0.46, p>0.05$.

\section{Procedure}

The Wechsler Adult Intelligence Scale (WAIS) Verbal and Performance IQs ${ }^{21}$ were used as indicators of intellectual functioning. Verbal learning and memory were assessed by a revised, 12 word, 12 trial Selective Reminding Memory Test $^{23} 24$ which has been shown to characterise problems in long term memory after severe $\mathrm{CHI} .^{8}$ After the first trial, the patient was reminded of only those words which were not recalled on the previous trial. A word was defined as stored (that is, long term storage) if it was recalled on two consecutive trials, the second without reminding by the examiner. Consistent long term retrieval (CLTR) (that is, consecutive recall of a stored word as far as the 12th trial) was employed as an index of long term verbal memory. Apart from CLTR, other measures on the Selective Reminding Test included cued recall (presentation of the first two or three letters of the target word), recognition (identifying the target word when it was displayed with three distractors), and 30 minute delayed recall.

Visual memory was evaluated by the Continuous Recognition Memory Test. ${ }^{7}$ After viewing a series of 20 different line drawings of common objects, the patient was asked to identify 100 additional drawings as old (that is, previously presented) or new (that is, presented for the first time). Of the test series, there were 40 recurrences (old) and 60 pictures presented only once (new). The probabilities of hits (correctly identifying a previously seen picture as old) and false alarms (incorrectly identifying a new picture as old) were used to calculate $\mathrm{d}^{\prime},{ }^{25}$ an unbiased estimate of memory sensitivity. At the completion of the recognition test, a matching to sample procedure consisting of the same line drawings was administered to rule out a primary deficit in visual discrimination. All patients and controls obtained discrimination scores within normal limits.

Patients were scheduled for assessment at regular intervals, including baseline (that is, after resolution of posttraumatic amnesia), 6 months, 1 year, 2 years and 3 years as part of an ongoing project to examine recovery of function. In view of variation in the actual follow-up intervals due to scheduling difficulty and disability, we analysed the data collected at two wider follow-up windows in which the WAIS, Selective Reminding and recognition memory were concurrently administered. The first occasion was 5 to 15 months $(M=303.7$ days, $S D=103.0$ days $)$, and the second occasion was 16 to 42 months $(M=844.4$ days, $S D=250.8$ days). In the event that a patient was evaluated more than once during an interval (that is, had both a 2 and 3 year follow-up), we selected the most recent scores to reflect a stable level of outcome. There were no significant differences in the injury-test intervals between moderate and severe $\mathrm{CHI}$ patients at the five to 15 month window $(M=284 \cdot 1$ days in moderates versus 315.9 days in severes, $F(1,63)=1.47$, $p>0.05)$ or the 16 to 42 month interval $(M=822.5$ days for moderates versus $854 \cdot 2$ days in severes, $F(1,40)=0 \cdot 14$, p $>0.05$ ). 


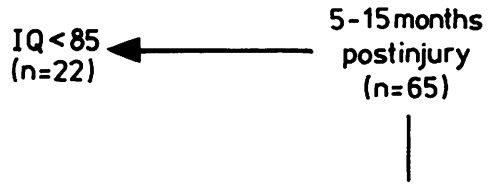

Normal IQ $(\geqslant 85)$<smiles>[AsH]</smiles>

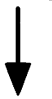

IQ-memory disparities $\left[\begin{array}{c}\text { Verbal IQ vs verbal memory } \\ \text { Performance IQ vs visual memory }\end{array}\right]$ Memory impaired

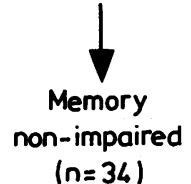

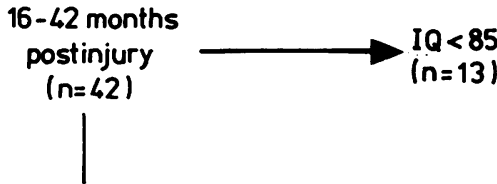

Normal IQ $(\geq 85)$

$(n=29)$

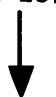

IQ-memory disparities $\left[\begin{array}{c}\text { Verbal IQ vs verbal memory } \\ \text { Performance IQ vs visual memory }\end{array}\right]$

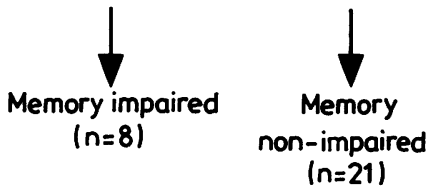

Fig 1 Diagram of patient flow and differentiation of memory impaired, memory unimpaired and globally impaired groups. Note that 20 patients were studied at both 5-15 months and 16-42 months.

\section{Results}

Intellectual and memory functioning 5 to 15 months after head injury

We obtained IQ and memory data for 25 moderate and 40 severe $\mathrm{CHI}$ patients at 5-15 months after injury. To characterise disproportionately impaired memory functioning (fig 1), we identified patients whose residual Verbal and Performance IQs were within the normal range of $\geqslant 85$ (that is, one standard deviation below the population mean of 100 or higher). Nineteen (76\%) of the moderate $\mathrm{CHI}$ patients and $24(60 \%)$ of the severe $\mathrm{CHI}$ patients obtained both Verbal and Performance IQ scores of 85 or above.

CLTR and d' scores were transformed into standard scores (that is, mean of 100 with a standard deviation of 15) to facilitate comparison with postinjury IQ. This transformation involved subtracting from the patient's raw score the mean obtained in a sample of 50 normal young adults and dividing by the standard deviation of the normative group. The resultant $\mathrm{Z}$ score was then multiplied by 15 and 100 points were added.

Figure 2 depicts the median IQs and memory standard scores of patients who attained this criterion of relatively normal (but not necessarily recovered) postinjury intellectual functioning as well as the median scores of 18 controls fitting this pattern (a single control subject had an IQ below 85). Variability within each group is given by the interquartile range (25th and 75th percentiles). One-way analyses of varianceo on each measure indicated that the Verbal IQs, $\mathrm{F}(2,58)=1.39, \mathrm{p}>0.05$, and Performance IQs, $\mathbb{D}$ $F(2,58)=0.67, p>0.05$, of the three groups were comparable despite disparities in memory functioning. Verbal memory, as measured by CLTR of the

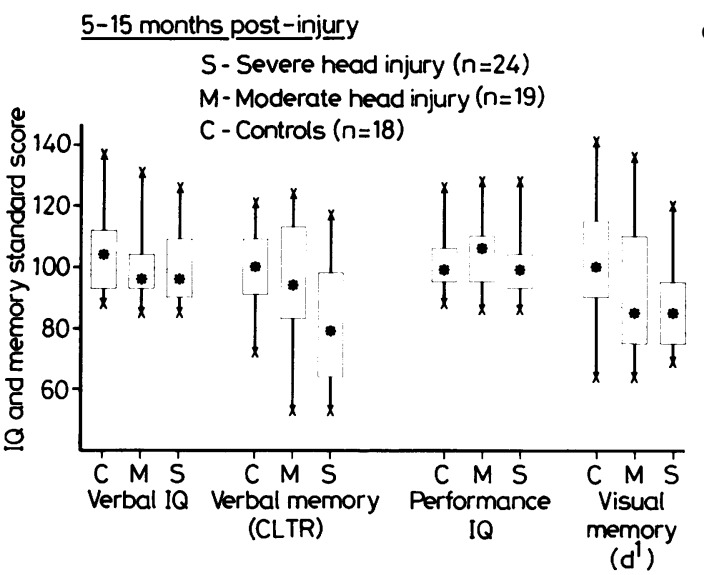

Fig 2 Box-plots depicting the distribution of $I Q$ and transformed memory scores for controls, moderate and severe head-injured patients who obtained $I Q$ scores within the normal range $(\geqslant 85)$ at 5-15 months after injury. Each asterisk signifies the median, whereas the upper and lower horizontal lines of each bar indicate the 75th and 25th percentile scores, respectively. The maximum and minimum scores are depicted by the letter " $X$ ". 
Selective Reminding Test, showed significant group differences, $F(2,58)=3.93, p<0.05$. A Scheffe post hoc analysis of the cell means revealed that severely injured patients obtained lower CLTR standard scores than controls on the Selective Reminding Test $(p<0.05)$, whereas moderately injured patients did not differ from either of the other groups. In addition, there was a trend toward a group difference in recognition memory (d'), $F(2,58)=2.92, p=0.06$, with severely injured patients again performing below the level of controls while patients with moderate injuries were intermediate.

To examine disparities between IQ and memory, we subtracted the CLTR standard score from the Verbal IQ and the recognition memory standard score from the Performance IQ for every patient and control. This strategy was employed to facilitate comparison of memory and IQ for similar types of material (that is, auditory-verbal, visual-pictorial). Disproportionate memory impairment was defined by standard scores on both memory tests which were below 85 and at least 15 points less than the corresponding Verbal or Performance IQ score (VIQ $>$ CLTR, PIQ > CRM). Accordingly, three out of 19 moderate $\mathrm{CHI}(16 \%)$ and six out of 24 severe $\mathrm{CHI}(25 \%)$ patients showed this pattern versus none of the controls. A preliminary chi square analysis indicated a nearly significant association between severity group (that is, control, moderate, severe) and memory impairment, $\chi^{2}(2)=5 \cdot 13, p=0 \cdot 08$. Post hoc Fisher's exact tests indicated a trend for a higher proportion of generalised memory impairment in severely injured patients versus controls, $\chi^{2}(1)=3.41, p=0.06$.

\section{Intellectual and memory functioning 16 to 42 months after head injury}

Memory and IQ data were collected during the interval of 16 to 42 months after injury for 13 moderate and 29 severe head injured patients (fig 1). Twelve (92\%) of the moderate patients had IQs of 85 or greater, whereas $17(59 \%)$ of the severely injured cases revealed this level of intellectual function. Figure 3 indicates the median IQs and memory standard scores of patients and controls with relatively preserved intellectual functioning. Similar to the findings at 5-15 months, the Verbal, $\mathrm{F}(2,44)=1.44, \mathrm{p}>0.05$, and Performance IQs, $F(2,44)=0.82, p>0.05$, of the patient groups and controls were comparable. However, the verbal memory standard scores were significantly different, $F(2,44)=6.67, p<0.01$, with severely injured patients again exhibiting consistent retrieval of fewer words than moderately injured patients and controls. Recognition memory standard scores for the severe $\mathrm{CHI}$ patients tended to fall below those of the moderate patients and controls, a trend

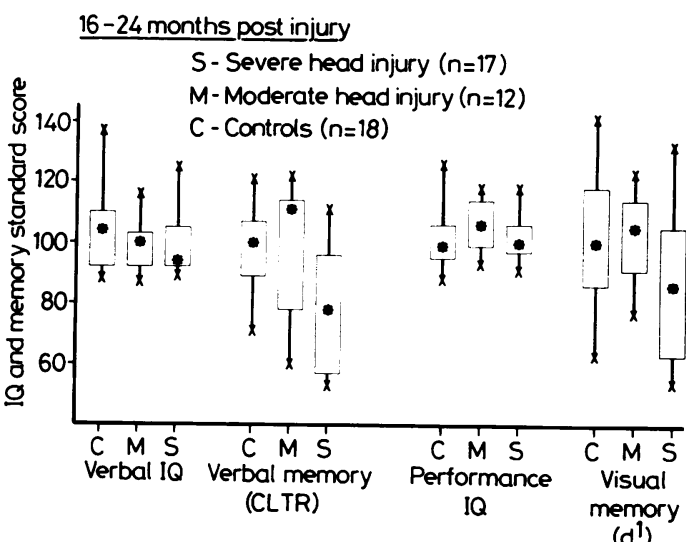

(d)

Fig 3 Box-plots depicting the distribution of $I Q$ and transformed memory scores for controls, moderate and severe head-injured patients who obtained $I Q$ scores in the preserved range ( $\geqslant 85$ ) at $16-42$ months postinjury. Each asterisk signifies the median, whereas the upper and lower horizontal lines of each bar indicate the 75th and 25th percentile scores. The maximum and minimum scores are depicted by the letter " $X$ ".

which approached significance, $F(2,44)=2 \cdot 77$, $p=0.07$.

Two out of the 12 patients with moderate injuries evidenced disproportionate memory disturbance as both memory scores fell below 85 with at least a 15 point difference in IQ (VIQ vs. CLTR; PIQ vs. CRM), whereas six out of 17 severely injured patients demonstrated memory disorder according to this criterion. A chi square analysis revealed a significant difference in the proportion of memory impaired patients according to severity, $\chi^{2}(2)=7.71, p<0.05$. Post hoc Fisher's exact tests confirmed that a higher proportion of severely injured patients exhibited generalised memory impairment versus controls, $x^{2}(1)=5.38, \mathrm{p}<0.05$, but other pairwise comparisons fell short of significance.

\section{Features of the memory-IQ discrepancy}

We examined the presence of cognitive features associated with the manifestation of generalised memory disturbance despite relatively preserved Verbal and Performance IQs (see table 2) by non-parametric techniques appropriate for small sample size. ${ }^{26}$ Although our two memory impaired groups had IQs of 85 or greater, they tended to have lower post-injury intellectual functioning than the comparatively unimpaired patients at both testing occasions. Pairwise comparisons by the Mann-Whitney U Test confirmed that the Verbal IQs of memory impaired CHI patients were significantly below those of unimpaired cases 
studied from five up to 15 months postinjury $(p<0.05)$ and from 15 months to 42 months $(\mathrm{p}<0.01)$. However, disparities in Performance IQs reached significance only for the scores obtained from 5 to 15 months $(p<0.05)$.

As reflected by the summary of Selective Reminding test data in table 2, retrieval of words by cues and recognition memory of target words were significantly lower $(p<0.01)$ in patients exhibiting a generalised memory impairment at $16-42$ months as compared with the performance of relatively unimpaired CHI patients. Moreover, the memory impaired group recalled fewer words after a delay of 30 minutes than the unimpaired group at the 5 to 15 months $(p<0.05)$ and 16 to 42 months $(p<0.01)$ examinations. In contrast, table 2 indicates similar digit span scaled scores in these groups at both testing occasions $(p>0.05)$.

Relationship of memory disorder to neurological indices and computed tomographic findings

The period of disturbed consciousness (inability to follow commands) tended to be longer in the patients who exhibited generalised memory disturbance than the unimpaired patients (table 3), a difference which did not approach significance. Similarly, the GCS scores were not reliably different. Table 3 depicts an association between nonreactive pupils during the initial hospitalisation and generalised memory disturbance at 16-42 months after injury, whereas impaired eye movements did not differentiate the memory impaired versus unimpaired groups (according to Fisher's exact test of proportions).

Table 3 shows the number of patients classified according to the presence and site of hemispheric mass lesion (based on CT and surgical findings). A trend for an association between bilateral lesions and membership in the memory impaired group $(33 \%)$ at $5-15$ months as compared with the unimpaired $(12 \%)$ patients was nonsignificant. Within the series examined 16 to 42 months after injury, table 3 shows that a significantly greater percentage of the memory impaired patients $(38 \%)$ had bilateral lesions than the patients without memory impairment as defined here $(0 \%)$. This association with bilateral brain lesions may reflect our definition of a memory deficit as a generalised impairment involving both verbal and pictorial material. Other differences in presence and site of hemispheric lesion in relation to memory impairment were less impressive. We postulated that patients showing disproportionate memory disturbance would be more likely to have incurred temporal lobe lesions. However, only one memory impaired patient had CT evidence of a temporal lobe lesion, as compared with five cases of frontal lesions. Among the patients with unimpaired memory, temporal lobe lesions were present in three cases. Of the

Table 2 Intellectual and memory functioning*

\begin{tabular}{|c|c|c|c|c|c|c|}
\hline & \multirow[b]{2}{*}{ Verbal IQ } & \multirow[b]{2}{*}{ Performance $I Q$} & \multirow{2}{*}{$\begin{array}{l}\text { Digit span } \\
\text { scaled score }\end{array}$} & \multicolumn{3}{|c|}{ Selective reminding } \\
\hline & & & & Recognition & Cued recall & 30 minute delay \\
\hline \multicolumn{7}{|l|}{$\begin{array}{l}\text { 5-15 months } \\
\text { Memory impaired } t\end{array}$} \\
\hline $\begin{array}{l}\text { Median } \\
\text { Range } \\
(\mathbf{N}) \\
\text { Memory unimpairedt }\end{array}$ & $\begin{array}{l}92 \cdot 0^{\circ} \\
85-110 \\
(9)\end{array}$ & $\begin{array}{l}93 \cdot 0^{\mathrm{c}} \\
87-101 \\
(9)\end{array}$ & $\begin{array}{l}9 \cdot 0 \\
6-15 \\
(9)\end{array}$ & $\begin{array}{l}12 \cdot 0 \\
7-12 \\
(8)\end{array}$ & $\begin{array}{l}8 \cdot 5 \\
4-10 \\
(8)\end{array}$ & $\begin{array}{l}7 \cdot 0^{\circ} \\
1-9 \\
(7)\end{array}$ \\
\hline $\begin{array}{l}\text { Median } \\
\text { Range } \\
\text { (N) } \\
\text { Globally impairedt }\end{array}$ & $\begin{array}{l}98 \cdot 5^{n} \\
89-131 \\
(34)\end{array}$ & $\begin{array}{l}103 \cdot 0^{c} \\
86-128 \\
(34)\end{array}$ & $\begin{array}{c}10 \cdot 0 \\
4-16 \\
(32)\end{array}$ & $\begin{array}{l}12 \cdot 0^{i} \\
7-12 \\
(25)\end{array}$ & $\begin{array}{l}10 \cdot 0^{1} \\
1-11 \\
(27)\end{array}$ & $\begin{array}{c}10 \cdot 0^{0, p} \\
0-12 \\
(24)\end{array}$ \\
\hline $\begin{array}{l}\text { Median } \\
\text { Range } \\
\text { (N) }\end{array}$ & $\begin{array}{l}83 \cdot 0^{2} \\
68-108 \\
(22)\end{array}$ & $\begin{array}{l}79 \cdot 0^{c} \\
60-103 \\
(22)\end{array}$ & $\begin{array}{c}7 \cdot 0^{x} \\
4-10 \\
(22)\end{array}$ & $\begin{array}{c}10 \cdot 0^{i} \\
0-12 \\
(20)\end{array}$ & $\begin{array}{l}6 \cdot 5^{1} \\
0-11 \\
(20)\end{array}$ & $\begin{array}{l}6 \cdot 0^{p} \\
0-12 \\
(17)\end{array}$ \\
\hline \multicolumn{7}{|l|}{$\begin{array}{l}16 \text { months }-42 \text { months } \\
\text { Memory impairedt }\end{array}$} \\
\hline $\begin{array}{l}\text { Median } \\
\text { Range } \\
\text { (N) } \\
\text { Memory unimpairedt }\end{array}$ & $\begin{array}{l}91 \cdot 0^{b} \\
87-104 \\
(8)\end{array}$ & $\begin{array}{l}99 \cdot 0^{d} \\
90-110 \\
(8)\end{array}$ & $\begin{array}{l}9 \cdot 0^{9} \\
7-14 \\
(8)\end{array}$ & $\begin{array}{l}11 \cdot 5^{5} \\
7-12 \\
(6)\end{array}$ & $\begin{array}{l}5 \cdot 5^{\mathrm{m}} \\
1-9 \\
(8)\end{array}$ & $\begin{array}{l}2 \cdot 0^{9} \\
0-6 \\
(6)\end{array}$ \\
\hline $\begin{array}{l}\text { Median } \\
\text { Range } \\
\text { (N) } \\
\text { Globally impaired } \neq\end{array}$ & $\begin{array}{l}103 \cdot 0^{\mathrm{b}} \\
89-123 \\
(21)\end{array}$ & $\begin{array}{l}102 \cdot 0^{e} \\
91-119 \\
(21)\end{array}$ & $\begin{array}{c}10 \cdot 0^{\mathrm{h}} \\
4-16 \\
(20)\end{array}$ & $\begin{array}{l}12 \cdot 0^{\mathrm{j}, \mathrm{k}} \\
12 \\
(14)\end{array}$ & $\begin{array}{l}10 \cdot 0^{\mathrm{m}, \mathrm{n}} \\
3-12 \\
(17)\end{array}$ & $\begin{array}{l}10 \cdot 5^{\mathrm{q}, \mathrm{r}} \\
2-12 \\
(12)\end{array}$ \\
\hline $\begin{array}{l}\text { Median } \\
\text { Range } \\
\text { (N) }\end{array}$ & $\begin{array}{l}82 \cdot 0^{b} \\
72-105 \\
(13)\end{array}$ & $\begin{array}{l}81 \cdot 0^{d, e} \\
65-102 \\
(13)\end{array}$ & $\begin{array}{l}7 \cdot 0^{g, h} \\
4-12 \\
(13)\end{array}$ & $\begin{array}{c}12 \cdot 0^{k} \\
0-12 \\
(11)\end{array}$ & $\begin{array}{l}8 \cdot 0^{\mathrm{n}} \\
2-11 \\
(11)\end{array}$ & $\begin{array}{l}7 \cdot 0^{r} \\
2-12 \\
(9)\end{array}$ \\
\hline
\end{tabular}

*A common suprascript letter denotes a significant difference between groups of 0.05 or less. tVerbal and Performance IQs were 85 or above.

†IQ was below 85 on the Verbal and/or Performance Scales of the WAIS. 
Disproportionately severe memory deficit in relation to normal intellectual functioning after closed head injury

Table 3 Neurologic indices of injury in memory impaired vs. unimpaired head injured patients*†

\begin{tabular}{|c|c|c|c|c|c|c|c|c|c|c|}
\hline & \multirow{3}{*}{$\begin{array}{l}\text { Duration } \\
\text { of impaired } \\
\text { consciousness }+\end{array}$} & \multirow{3}{*}{$\begin{array}{l}\text { Lowest } \\
\text { recorded } \\
\text { GCS } \\
\text { score }\end{array}$} & \multicolumn{4}{|c|}{ Type of injury } & \multirow{2}{*}{\multicolumn{2}{|c|}{ Pupillary reactivity }} & \multirow{2}{*}{\multicolumn{2}{|c|}{$\begin{array}{l}\text { Oculocephalic/ } \\
\text { oculovestibular } \\
\text { response }\end{array}$}} \\
\hline & & & \multicolumn{4}{|c|}{ Hemispheric mass lesion§ } & & & & \\
\hline & & & Diffuse & Left & Right & Bilat & Normal & Abnormal & Normal & Abnormal \\
\hline \multicolumn{11}{|l|}{ 5-15 months } \\
\hline \multirow{3}{*}{$\begin{array}{l}\text { Memory } \\
\text { impaired } \\
(\mathrm{N}=9) \\
\text { Memory } \\
\text { unimpaired } \\
(\mathrm{N}=34) \\
\text { Globally } \\
\text { impaired } \\
(\mathrm{N}=22)\end{array}$} & $\begin{array}{l}\text { Median }=16 \cdot 0 \text { days } \\
\text { Range }=0-30\end{array}$ & $\begin{array}{l}\text { Median }=6.0 \\
\text { Range }=4-15\end{array}$ & 4 & 1 & 1 & 3 & 5 & 4 & 6 & 3 \\
\hline & $\begin{array}{l}\text { Median }=2 \cdot 0 \text { days } \\
\text { Range }=0-56\end{array}$ & $\begin{array}{l}\text { Median }=7 \cdot 0 \\
\text { Range }=3-15\end{array}$ & 18 & 7 & 5 & 4 & 30 & $4^{e}$ & 29 & $5^{h}$ \\
\hline & $\begin{array}{l}\text { Median }=10 \cdot 0 \text { days } \\
\text { Range }=0-60\end{array}$ & $\begin{array}{l}\text { Median }=6.0 \\
\text { Range }=3-15\end{array}$ & 10 & 2 & 6 & 4 & 11 & $11^{\mathrm{e}}$ & 11 & $11^{\mathrm{h}}$ \\
\hline \multicolumn{11}{|c|}{$>15$ months -42 months } \\
\hline $\begin{array}{l}\text { Memory } \\
\text { impaired } \\
(\mathrm{N}=8)\end{array}$ & $\begin{array}{l}\text { Median }=9 \cdot 5 \text { days } \\
\text { Range }=1-30\end{array}$ & $\begin{array}{l}\text { Median }=6.5 \\
\text { Range }=4-12\end{array}$ & 4 & 1 & 0 & $3^{c}$ & 3 & $5^{f}$ & 5 & 3 \\
\hline $\begin{array}{l}\text { Memory } \\
\text { unimpaired } \\
(\mathrm{N}=2 \mathrm{l})\end{array}$ & $\begin{array}{l}\text { Median }=1.0 \text { days }^{\mathrm{a}} \\
\text { Range }=0-90\end{array}$ & $\begin{array}{l}\text { Median }=8 \cdot 0^{b} \\
\text { Range }=4-15\end{array}$ & 11 & 3 & 7 & $0^{\text {c.d }}$ & 18 & $3^{\mathrm{f}, \mathrm{g}}$ & 17 & 4 \\
\hline $\begin{array}{l}\text { Globally } \\
\text { impaired } \\
(\mathrm{N}=13)\end{array}$ & $\begin{array}{l}\text { Median }=18.0 \text { days }^{\mathrm{a}} \\
\text { Range }=0.010-150\end{array}$ & $\begin{array}{l}\text { Median }=6.0^{b} \\
\text { Range }=4-14\end{array}$ & 2 & 4 & 3 & $4^{d}$ & 5 & $8^{g}$ & 6 & 7 \\
\hline
\end{tabular}

*A common suprascript letter denotes a significant difference between groups of 0.05 or less.

+GCS = Glasgow Coma Scale, Bilat = bilateral.

+ Defined by the interval until the patient consistently followed commands.

$\S$ Based on computed tomographic findings within 24 hours of injury and surgical reports.

globally impaired patients, 12 had frontal and six had temporal lesions.

Distinctive characteristics of globally impaired head injured patients

We also examined the demographic and clinical features of patients who were excluded from the main analyses because they obtained Verbal and/or Performance IQ scores less than 85 (that is, the Globally Impaired group in tables 2 and 3). Age and education did not differ significantly across the groups at either testing occasion (table 2). In contrast, the globally impaired patients (IQ below 85) had lower GCS scores and longer durations of disturbed consciousness than unimpaired patients tested at 16-42 months (table 3). Those patients exhibiting a disproportionate memory disturbance had GCS scores and durations of impaired consciousness which were intermediate between these groups. Nonreactive pupils were more common in patients with follow-up IQs below 85 as compared with the unimpaired patients studied at 16-42 months after injury (chi-square and post hoc Fisher's exact test, $p<0.01$ ). In addition, the presence of oculocephalic/oculovestibular disturbance differentiated intellectually impaired versus unimpaired patients at 5 to 15 months postinjury $(p<0.01)$.

A chi-square analysis at the second testing occasion indicated significant $(p<0.05)$ differences in the proportion of patients classified according to the presence and site of a focal mass lesion. Post hoc Fisher's exact tests suggested group differences $(p<0.05)$ between intellectually impaired and memory unimpaired patients. As seen in table 3, a greater percentage of intellectually impaired patients sustained bilateral lesions $(31 \%)$ than unimpaired patients $(0 \%$ bilateral). In contrast, diffuse injuries predominated in unimpaired patients $(52 \%)$ relative to intellectually impaired $(15 \%)$ patients.

\section{Discussion}

Our definition of a relatively specific memory disorder specified that intellectual functioning recovered to at least the low normal range. Consequently, we infer that residual memory impairment after $\mathrm{CHI}$ is frequently disproportionate to relatively normal intellectual functioning. In view of the finding that about one-fourth of the patients studied in each follow-up interval were considered to have a generalised memory disturbance on both verbal and visual material, it is questionable whether memory disorder present at 1 year recovers substantially during the next 2 to 3 years. However, this surmise must be interpreted cautiously pending collection of serial memory test data. All patients in this study complied with follow-up and were capable of undergoing detailed neuropsychological assessment. Therefore, our results can be extrapolated only to survivors of $\mathrm{CHI}$ who recover to a testable level. In view of the exclusion criteria concerning previous head injury, 
neuropsychiatric disorder and substance abuse, it is unlikely that the memory problems documented herein represent a pre-existing condition. Apart from confirming previous findings ${ }^{13-6}$ that memory impairment often persists after resolution of PTA, this study also supports other investigations ${ }^{11}$ in demonstrating that memory disorder is present despite recovery of relatively normal intellectual functioning.

The relationship between severity of $\mathrm{CHI}$ and persistent memory deficit in this study varied according to the neurological indices. Nonreactive pupils during the acute state of injury were more common in patients who were left with a relatively specific memory deficit as compared with patients who had normal memory functioning at the time of follow-up. However, the GCS score and duration of impaired consciousness were comparable in the memory impaired and unimpaired patients. In addition, it appeared that memory impaired patients more frequently sustained bilateral hemispheric mass lesions. As might be expected, severity of injury tended to be greater in patients who had global cognitive impairment marked by defective scores on memory and IQ tests. This latter finding is consistent with previous studies which have reported on concurrent impairment of intellectual function and memory. ${ }^{2}$ Further research is necessary to determine whether the proportion of our patients exhibiting persistent memory disorder is representative of survivors of similar injuries at other centres who recover to a testable level. Although we did not observe an excess of temporal lobe lesions in the memory impaired patients, a recent study using magnetic resonance imaging ${ }^{27}$ found multifocal lesions in the frontal, temporal, parietal and occipital lobes in a patient with an apparently diffuse injury. Advances in neuroimaging may reveal relationships between residual memory disorder and neuroanatomic locus of lesion or hypometabolism which are undetected by CT.

Is it appropriate to refer to residual memory deficit after $\mathrm{CHI}$ as an amnesic disorder? All patients whom we designated as memory impaired had intact orientation and were no longer in PTA according to a brief test of gross memory and appreciation of time, place, person and circumstances of injury. To the extent that anterograde amnesia "refers to impairment in learning new material", ${ }^{28}$ we contend that this clinical picture can emerge after $\mathrm{CHI}$ with the proviso that intellectual functioning is within the normal range. $A$ portion of our CHI patients had residual intellectual and memory deficits, a pattern consistent with global cognitive impairment rather than amnesic disorder.

To many clinicians and investigators, the term "amnesia" connotes a condition characterised by loss of memory over periods as brief as a few minutes associated with disorientation, if not confabulation. ${ }^{29}$
Although these clinical features are frequently present in patients with alcoholic Korsakoff's syndrome, ${ }^{30}$ there is in fact wide variability in the severity of amnesia and the disparity between memory and intellectual functions in Korsakoff patients. ${ }^{1213}$ The requirement for a disparity of at least one standard deviation between Verbal IQ and verbal memory and between Performance IQ and visual memory in the present study is similar to the neuropsychological criteria typically employed to diagnose amnesia in patients with alcoholic Korsakoff's syndrome. Future studies could examine whether there are distinctive features of memory disorder after $\mathrm{CHI}$ as compared with alcoholic Korsakoff syndrome and other causes of amnesic disorder. Finally, the correspondence between residual memory disorder as defined herein for CHI patients and its manifestations in everyday activities remains to be investigated. ${ }^{31}$

This investigation was supported by the Javits Neuroscience Investigator Award, NS 21889, Moody Foundation grants \$84-152 and \$84-152A and a grant from the Dallas Rehabilitation Foundation. We thank Lori A Baxter for her assistance in data analysis and Liz Zindler for manuscript preparation.

\section{References}

1 Russell WR. The Traumatic Amnesias. New York: Oxford University Press, 1971.

2 Alexandre A, Colombo F, Nertempi P, Benedetti A. Cognitive outcome and early indices of severity of head injury. $J$ Neurosurg 1983;59:751-61.

3 Brooks DN. Memory and head injury. J Nerv Ment Dis 1972; 155:350-5.

4 Brooks DN. Recognition memory after head injury: a signal detection analysis. Cortex 1974;10:224-30.

5 Brooks DN. Recognition memory and head injury. $J$ Neurol Neurosurg Psychiatry 1974;37:794-801.

6 Brooks DN. Long and short term memory in head injured patients. Cortex 1975;11:329-40.

7 Hannay HJ, Levin HS, Grossman RG. Impaired recognition memory after head injury. Cortex 1979;15:269-83.

8 Levin HS, Grossman RG, Rose JE, Teasdale G. Long-term neuropsychological outcome of closed head injury. $J$ Neurosurg 1979;50:412-22.

9 Teasdale G, Jennett B. Assessment of coma and impaired consciousness: A practical scale. Lancet 1974;ii:81-4.

10 Levin HS, Benton AL, Grossman RG. Neurobehavioral Consequences of Closed Head Injury. New York: Oxford University Press, 1982.

11 Stuss DT, Ely P, Hugenholtz $\mathbf{H}$, et al. Subtle neuropsychological deficits in patients with good recovery after closed head injury. Neurosurgery 1985;17:41-7.

12 Jacobson RR, Lishman WA. Selective memory loss and global intellectual deficits in alcoholic Korsakoff's syndrome. Psychol Med 1987;17:649-55.

13 Squire LR, Shimamura AP. Characterizing amnesic patients for neurobehavioral study. Behav Neurosci 1986;100:866-77.

14 Warrington EK, Weiskrantz L. Amnesic syndrome: Consolidation or retrieval? Nature 1970;228:628-30. 
15 Warrington EK, Weiskrantz L. Further analysis of the prior learning effect in amnesic patients. Neuropsychologia 1978;16:169-77.

16 Butters N, Cermak LS. Alcoholic Korsakoff's Syndrome: an Information Processing Approach to Amnesia. New York: Academic Press, 1980.

17 Dikmen S, McLean A, Temkin N. Neuropsychological and psychosocial consequences of minor head injury. $J$ Neurol Neurosurg Psychiatry 1986;49:1227-32.

18 Gentilini M, Nichelli P, Schoenhuber R, et al. Neuropsychological evaluation of mild head injury. $J$ Neurol Neurosurg Psychiatry 1985;48:137-40.

19 Levin HS, Mattis S, Ruff RM, et al. Neurobehavioral outcome following minor head injury: A three-center study. J Neurosurg 1987;66:234-43.

20 Benton AL, Hamsher K deS. Multilingual Aphasia Examination. Iowa City: University of Iowa, 1976 (Manual, revised, 1978).

21 Wechsler D. Manual for the Wechsler Adult Intelligence Scale. New York: The Psychological Corporation, 1955.

22 Wilson RS, Rosenbaum G, Brown G, Rourke D, Whitman D, Grisell J. An index of premorbid intelligence. J Consult Clin Psychol 1978;46:1554-5.

23 Buschke H, Fuld PA. Evaluating storage, retention, and retrieval in disordered memory and learning. Neurology 1974;24: 1019-25.

24 Hannay HJ, Levin HS. Selective reminding test: An examination of the equivalence of four forms. J Clin Exp Neuropsychol 1985;7:251-63.

25 Green DM, Swets JA. Signal Detection Theory and Psychophysics. New York: Wiley, 1966.

26 Siegel S. Nonparametric Statistics for the Behavioral Sciences. New York: McGraw-Hill Book Company, 1956.

27 Levin HS, Handel SF, Goldman AM, Eisenberg HM, Guinto FC. Magnetic resonance imaging after "diffuse" nonmissile head injury. Arch Neurol 1985;42:963-8.

28 Kopelman MD. Amnesia: organic and psychogenic. $\mathrm{Br} J$ Psychiatry 1987;150:428-42.

29 Whitty CWM, Zangwill OL. Traumatic amnesia. In: Whitty CWM, Zangwill OL, eds. Amnesia: Clinical, Psychological and Medicolegal Aspects, 2nd ed. Boston: Butterworth, 1977.

30 Butters N. Alcoholic Korsakoff's syndrome: Some unresolved issues concerning etiology, neuropathology, and cognitive deficits. J Clin Exp Neuropsychol 1985;7:181-210.

31 Baddeley A, Harris J, Sunderland A, Watts KP, Wilson B. In: Levin HS, Grafman J, Eisenberg HM, eds. Neurobehavioral Recovery from Head Injury. New York: Oxford University Press, 1987. 